\title{
Building a three-dimensional structural model-A case study of a
}

\section{complex fault block}

\author{
Wang Weilin", a Liu Longlong ${ }^{2, b}$ An Hongliang ${ }^{1, ~ c}$ Wang Bo $^{1, ~ d}$ Liao Juan ${ }^{1, e}$ \\ ${ }^{1}$ PetroChina Changqing Oilfield Company, Xi'an, China \\ ${ }^{2}$ College of Resources Science \& Technology, Beijing Normal University, Beijing,China \\ aemail:wawl7_cq@petrochina.com.cn; bemail:liulonglong0309@126.com; \\ 'email:anhl7_cq@petrochina.com.cn;
}

Keywords:Fault block, Fault modeling, horizon modeling, structural modeling

Abstract:Structural complexity is obvious in WW fault block of A oilfield, mainly due to high fault development degree. Based on the study of core observation, high resolution sequence stratigraphy and seismic profile, the lower second sub-member of Shahejie Formation of WWfault block was subdivided into 58 layers. Three-dimensional structural model is constructed to display the occurrences of fault systems and horizon surfaces in the area. All wells' layering data, fault data and two-dimensional structural maps are integrated to build a 3-D structural model.

\section{Introduction}

At present, concerning the development situation of onshore reservoirs, especially the ones that have entered the middle or last period of development, geologists have been designed and utilized more and more software to simulate the distribution of remaining oil and gas in underground reservoir $^{[1,2]}$. Regardless of the mathematic theories, reservoir engineering fundamentals and other knowledge base, what all the software have in common is that they require a platform namely a structural model on which parameters and ideas could be populated. Faults of different sizes and stratums formed in different period are two main compositions of structure. Therefore, the primary mission of structural modeling is to describe faults and strata. Reservoir structure influences the underground well patterns directly and the interrelationship between faults also effects the injection-production matching relations as well as the subsurface pressure changing rules ${ }^{[3]}$. A 3-D structural model is also the foundational carrier for structural deformation analysis, fracture development and other simulation related to dynamic mechanics and strain recovery ${ }^{[4]}$.Predecessors' achievements about 3-D geologic modeling of Ww Fault block were limited ${ }^{[5,6]}$,especially in term of its complex structure. Hence, in order to study the remaining oil and gasdistribution, a 3-D model which aims to reflect the authentic condition about the underground is needed to be built.

\section{Stratigraphic Framework Modeling}

Stratigraphic framework is a concept of combined horizon surfaces or strata interfaces, generated by well tops through interpolation ${ }^{[7,}{ }^{8]}$.It could be understood that a stratigraphic framework is a set of united interfaces which convey the structural information of the overall reservoir. A 3-D structural model consists of fault models and horizon models. 


\section{Fault modeling}

The stratigraphic framework modeling starts with fault modeling. In general, 2-D seismic cross section or 3-D seismic cubes are used for fault modeling ${ }^{[5,6,7,8,9,10,11]}$.In this study, instead of such seismic files, eight 2-D top structural maps of each sand group are used for fault modeling. These maps not only show the faults originally interpreted based on seismic files, but also absorb the faults with small scales, recognized from long-term production recognition or well correlation (Fig1).Additionally, the quality of current seismic data are not enough to resolving the thin reservoir intervals. During the fault modeling process, fault points are utilized to accurately fix the faults in space (Fig2c).It is an iterative and interactive process to construct fault models. In practice, several quite small faults are ignored during the modeling process. Ultimately, a total number of 37 faults are estimated (Fig 2a, Fig 2b).

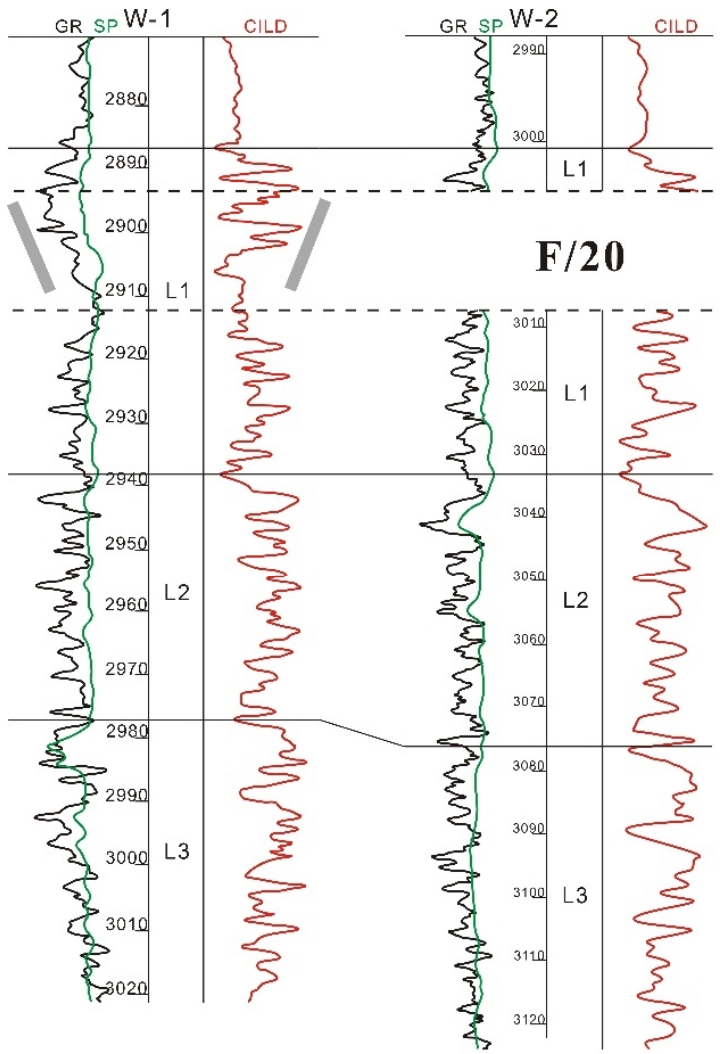

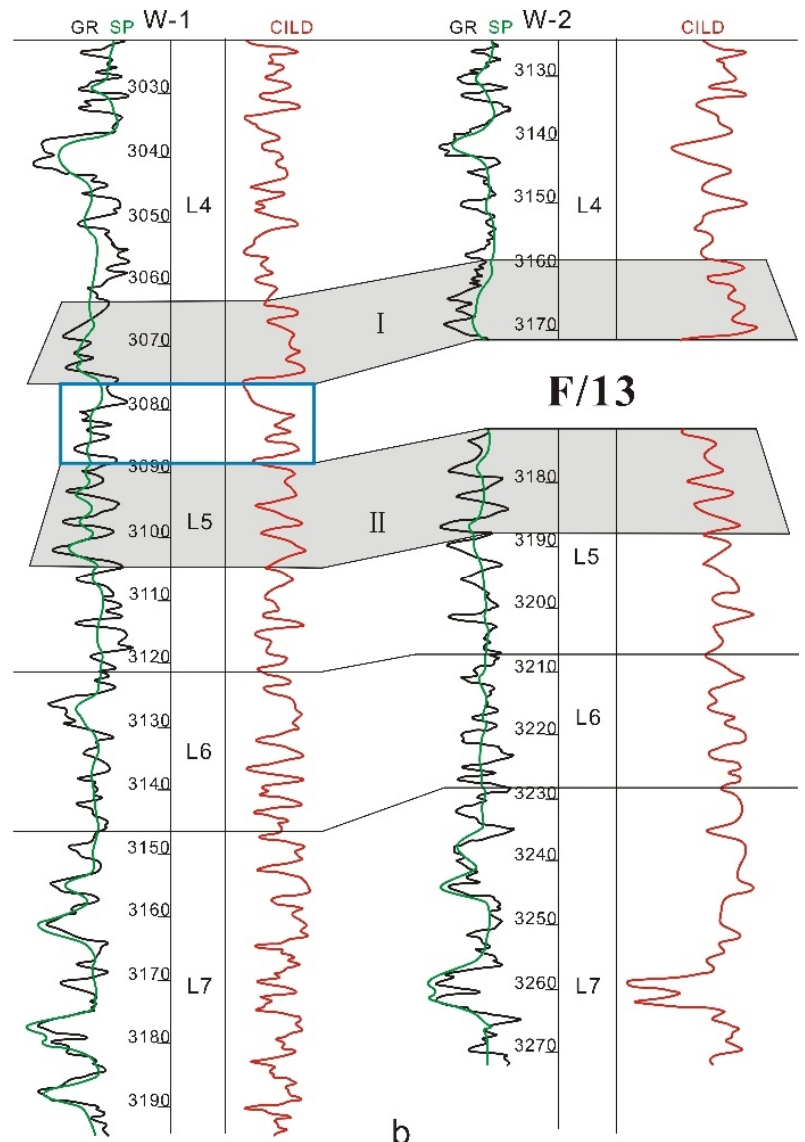

b

Figure 1Fault detection through well logs correlation. The well W-1 is used as a reference well with complete formation development. (a) A small-scale fault was discovered, logging responses started from the depth of $3008 \mathrm{~m}$ in well W-2, compared to the well W-1. The marked interval has low gamma ray (GR) values and high deep investigate induction conductivity (CILD) values, bell-shaped, while similar features are missing in the well W-2. (b) Logging characteristics shown in the blue box disappear suddenly in the well W-2. Combined curves demonstrated in part I and part II are steady for well correlation and the missing part between them can be interpreted to fault existence. 


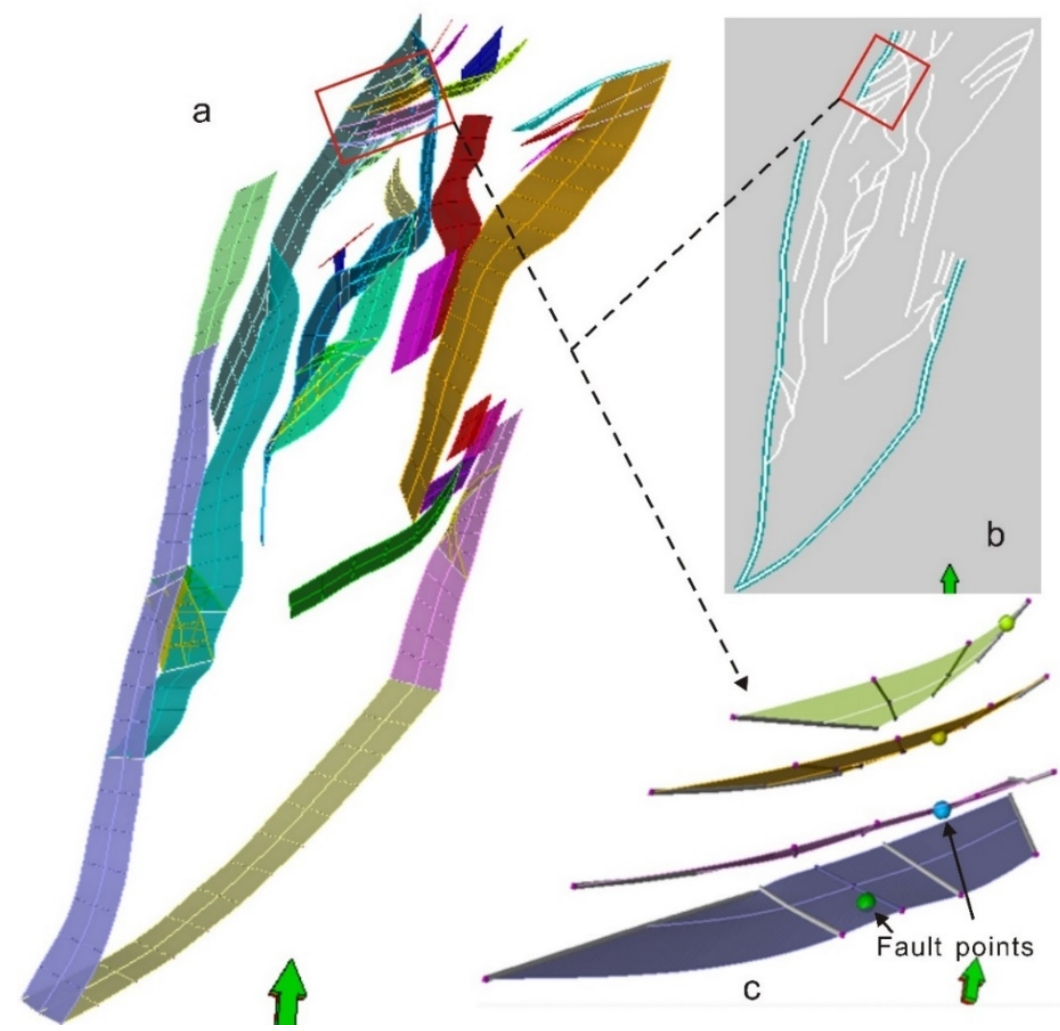

Fig 2 Fault models of Ww fault block. (a) 3-D view of fault models and each of them is colored differently. (b) 2-D distribution of modeled faults. The blue ones are used as part of model boundary. (c) Fault points used to shape faults.

\section{Horizon modeling}

After the fault models have been set up, interfaces namely horizon models are to build, limited by all the corresponding well tops (Fig 3b). A horizon model's continuity is affected if there are faults breaking the interfaces. In a structural sense, a horizon model reflects both the features of structural contour lines and the fault occurrences. As to a 3-D horizon model, its highlighting advantage is that it allows flexible angles of view to show the external strata appearance. For example, it's easy and quick to locate the structural highs or special structural characterization through intuitionistic color information (Fig 3a, Fig 3b). After a horizon model is built automatically, it's necessary to modify an original horizon model according to geological knowledge. Practically, horizon models could be used to check if fault models are precisely located through computing the distance between some certain wells and specified faults, using the measuring tool provided by the software, then comparing the results with the ones measured from 2-D structural maps. When both the fault models and horizon models are constructed, a stratigraphic framework of $\mathrm{Ww}$ fault block is finally established (Fig 3b).Specified structural features can be clearly observed in the 3-D geologic model. As shown in Fig 4a, the middle arrow (A) points to a horst, where has a maximum displacement in the north and gradually diminishes southwards. The arrow in the top (B) highlights a structural high location. The bottom two red arrows (C) highlight two grabens, where the horizon model is obviously distorted.

A 3-D structural model is finally established when the space between each horizon model is filled with geologic bodies, namely different colored "units" shown in the model (Fig 4c, Fig 4d).A 3-D gridded structural model is the basement for quantifying subsurface reservoir. Furthermore, stochastic microfacies modeling and physical property modeling can both be conducted for 
petroleum exploration and management.

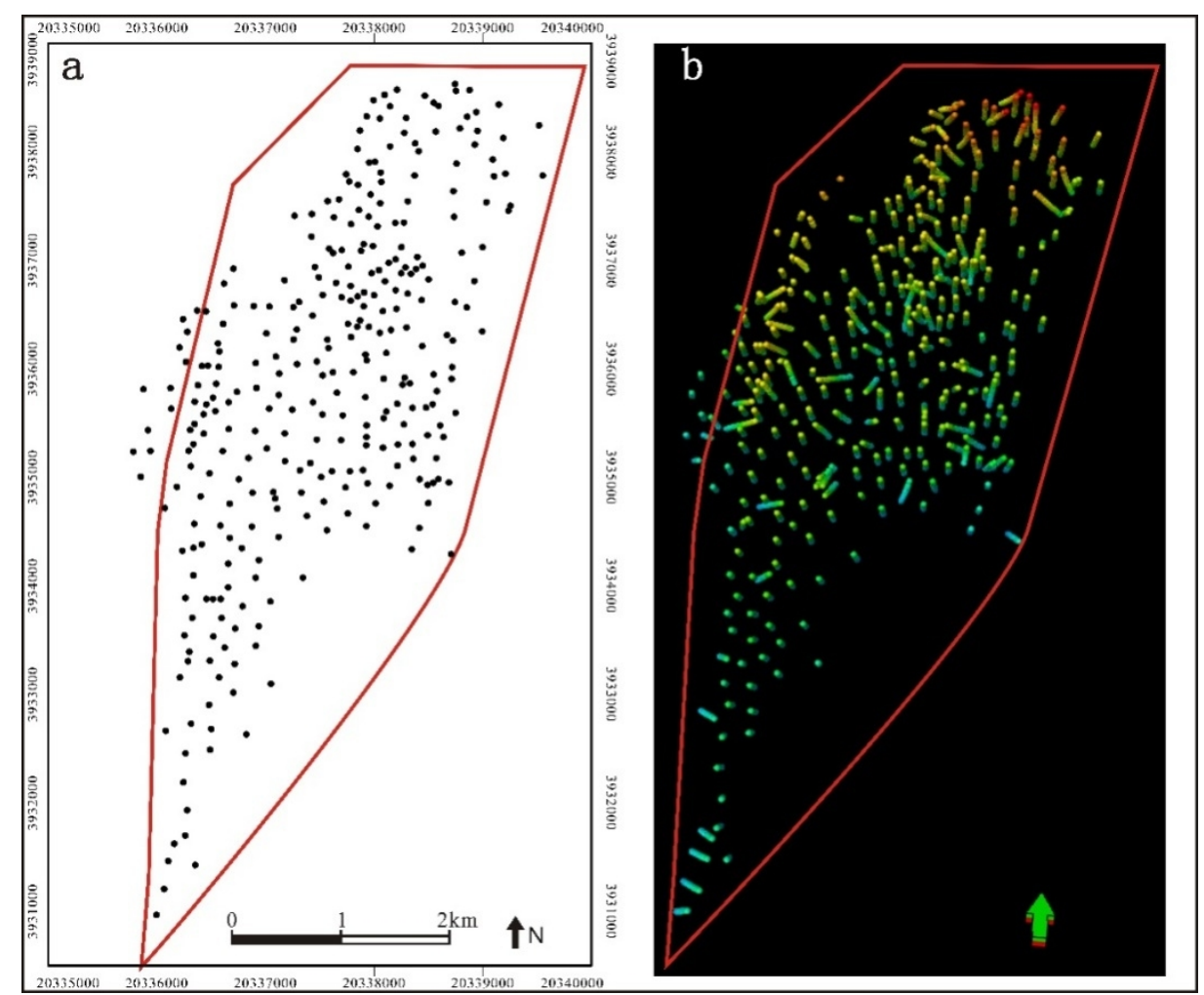

Fig 3(a) 2-D map view of all available wells and model boundary. (b) Layering data (well tops) of all wells used for modeling. 


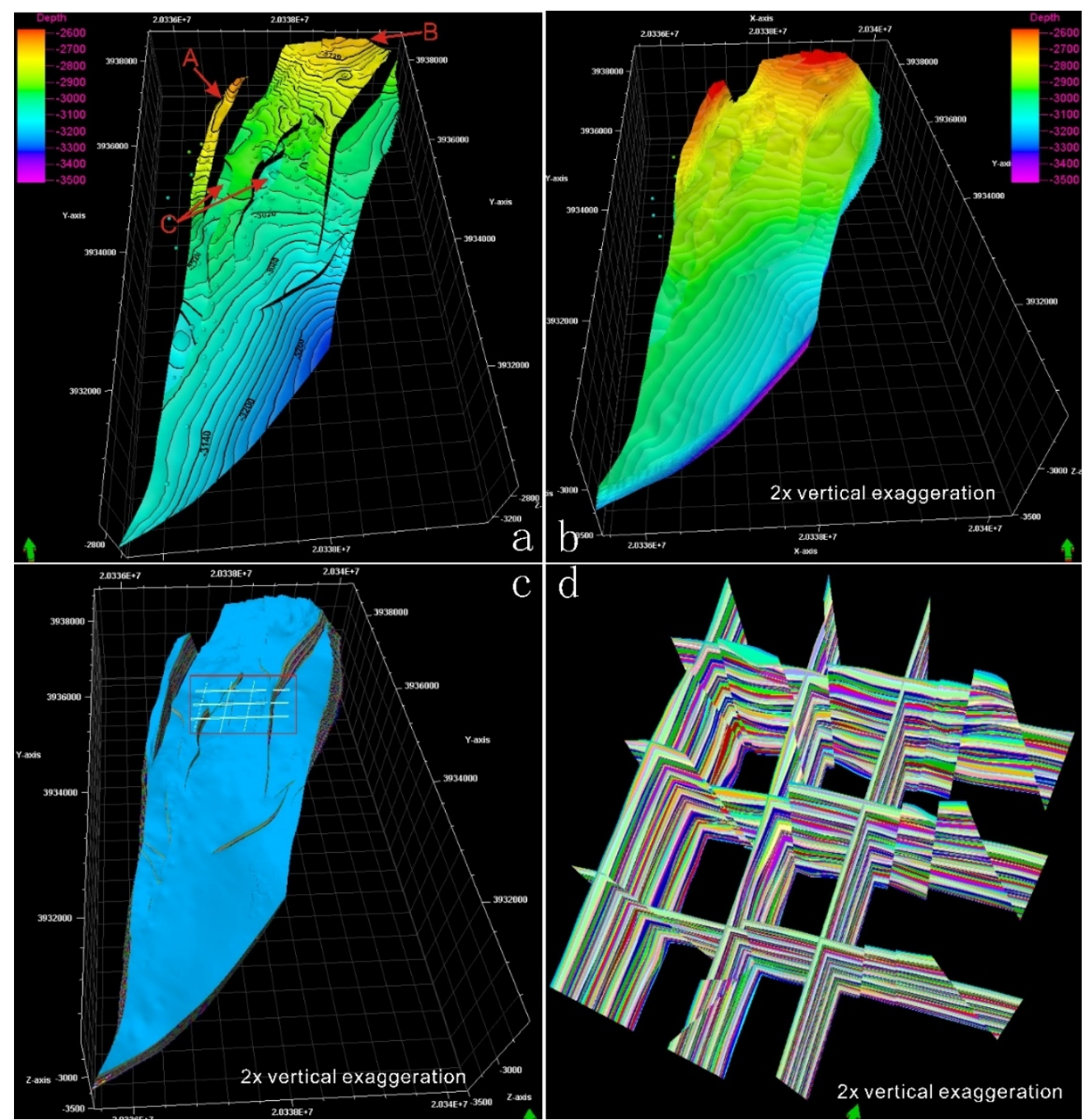

Fig 4Structural modeling of Ww fault block. (a) Horizon model of S2L4-3 layer reflecting that structural contour lines are affected by faults. (b) Stratigraphic framework made up of combined horizon models of Ww fault block. A total of fifty eight horizon models are built. (c) 3-D structural model of the studied area and it is generated by fulfilling entities, which stand for geological bodies, within the space between horizon models. (d) Specified fence diagram of the red box in (c). Geographical construction and formation patterns could be studied efficiently through cross sections.

\section{Conclusion}

Structural model of Ww fault block is established based on layering data, fault data and 2-D structural maps. The structural model not only improves our understanding of the reservoir structural features, but also provides a platform for quantified architectural element modeling and reservoir property computation.3-D structural model not only demonstrates faults and horizon surfaces in a full perspective, but also clearly shows some specified structural features such as horst and graben. Additionally, sections of different directions allow a comprehensive study on what structural patterns are like between wells. What's more, the structural model is the basement for depositional system study and reservoir physical property prediction.

\section{References}

[1] Guo M.L.Remaining Oil Distribution Research in Complex Fault- Block Oilfield with Numerical Simulation Technology. Fault-Block Oil \& Gas Field, 10(2003), 48-51 
[2] Han D.K.Discussions on concepts, countermeasures and technical routes for the redevelopment of high water-cut oilfields. Petroleum Exploration and Development, 2010, 37(2010), 583-591

[3] Ding F and Zhang J.L. Application of stochastic modeling technology in complex fault block-an example from Wen25 Block in Wenliu Oilfield. Journal of Beijing Normal University (Natural

Science). 50(2014), 205-211

[4] Guan S.W and He D.F. Theories and technical frameworks of complex structural modeling. Acta Petrolei Sinica, 32(2011), 991-999

[5] Gao H C, Zheng R C, Chen Y L, Han F M and Liu Y. Sequence stratigraphy of the Paleogene Shahejie Formation in Dongpu Sag, Bohai Bay Basin Oil \& Gas Geology. 32(2011), 839-850

[6] Gao H C, Zheng R C, Chen F L, Zhu D F and Liu X Y. Features of the Paleogene Shahejie Formation in the northern Dongpu Sag Geology in China. 38(2011), 356-373

[7] Qi L.S, Carr T.R and Goldstein R.H. Geostatistical three-dimensional modeling of oolite shoals, St Louis Limestone, southwest Kansas AAPG Bulletin. 91(2007), 69-96

[8] Sala P, Frehner M, Tisato N and Pfiffner O.A. Building a three-dimensional near-surface geologic and petrophysical model based on borehole data: A case study from Chémery, Paris Basin, France AAPG Bulletin. 97(2013), 1303-1324

[9] Ding F, Zhang JL and Xie J. Fine description of structure and sedimentary microfacies of Li32 block of Lijin oilfield, Dongying depression, China Arabian Journal of Geosciences. 7(2014), 1693-1704

[10] Li X, Zhang J.L, Yuan Y, Li C.L and Meng N.N. Sequence Stratigraphic Analysis and Integrated 3D Geological Modeling of M1 Block, Wenmingzhai Oilfield, Dongpu Depression, China Cent Eur J Geosci 5(2013), 374-386

[11] Liu L L, Zhang J L, Wang J K, Li C L, Yu J T, Zhang G X, Fan Z L, Wei G Q, Sun Z Q, Xue $\mathrm{H} \mathrm{H}, \mathrm{Yu}$ T, and Wang G Q 2015. Geostatistical modeling for fine reservoir description of Wei2 block of Weicheng oilfield, Dongpu depression, China Arab J Geosci. DOI: 10.1007/s12517-015-1924-2 